\title{
Effect of feed interval and feed type on splanchnic haemodynamics
}

\author{
Andrew J P Lane, Robert C Coombs, David H Evans, Roy J Levin
}

\begin{abstract}
Aim-To study the effect of enteral feeding on splanchnic blood flow velocity in preterm infants.

Method-Coeliac axis and superior mesenteric artery (SMA) blood flow velocity were measured longitudinally in a cohort of 61 babies using Doppler ultrasound.

Results-Babies fed 1 hourly had significantly higher preprandial SMA peak systolic velocity (PSV) than those fed 3 hourly (70 vs $53 \mathrm{~cm} / \mathrm{s})$. Those fed 1 hourly showed no postprandial change whereas those fed 3 hourly showed significant postprandial hyperaemia. This hyperaemia had longer latency (42 vs 27 mins) and smaller amplitude ( 31 vs 25 mins) after expressed breast milk compared with preterm formula. The addition of long chain polyunsaturated fatty acids to the formulas had no effect on the postprandial response.

Conclusion-Hourly bolus feeding leads to a persistent hyperaemic state in the SMA. The composition of feeds is an important determinant of the postprandial response of the SMA to 3 hourly feeding.

(Arch Dis Child Fetal Neonatal Ed 1998;79:F49-F53)
\end{abstract}

Keywords: splanchnic circulation; hyperaemia; bolus feeding; Doppler ultrasound

The advent of Doppler ultrasound has allowed blood flow velocity to be measured accurately and non-invasively. In healthy human adults a superior mesenteric artery (SMA) postprandial hyperaemia is reproducible and depends on the composition of the meal. ${ }^{1-4}$

In term infants the maximum response of the SMA is similarly dependent on feed composition. Hsu et al have shown a clinically significant SMA hyperaemia after a milk feed, a similar but quantitatively smaller response after an oral $5 \%$ glucose solution, and no significant change after water alone. ${ }^{5}$ While the latency of response in the human adult depends on feed composition this result was not repeated in term neonates. ${ }^{5}$ No postprandial change in coeliac axis blood flow velocity has been described in term neonates. ${ }^{56}$
The effect of feeding on the splanchnic haemodynamics of preterm babies has not been extensively investigated. Leidig examined the postprandial response of the SMA but only made three postprandial recordings and used these to draw conclusions regarding the time to peak response. ${ }^{7}$ This study concentrated on the relation of the postprandial response to postnatal age and feed volume but made no comment on the possible effect of feed interval. Gladman et $a l^{\beta}$ have examined the response to the first feed and have described an increase in both SMA and CA peak systolic velocity. They also reported that the blood flow velocity indices were not related to postnatal age, gestational age, or birthweight which contrasts with other data. ${ }^{6} 9$

The aims of this study were to define the effect of changing feed interval on splanchnic haemodynamics in a large cohort of preterm neonates. We also sought to describe the effect of different feed types on the response of the splanchnic vessels to bolus feeding and to compare the response to breast milk with the response to various formulas, with and without long chain polyunsaturated fatty acids.

\section{Methods}

As part of a larger longitudinal study of feed type and feed interval on splanchnic blood flow velocity we carried out 103 studies on 61 babies who were recruited during the first few days of life (table 1). Local ethical committee approval was obtained for the study and informed parental consent was obtained for each baby.

Data from babies fed at an interval of 3 hours or more (those fed 3 hourly, seven times daily, or on demand) were pooled to form one group of babies fed $\geqslant 3$ hourly. Babies fed 1,2 , or $\geqslant 3$ hourly were not significantly different with respect to gestation or birthweight. Weight at the time of study was significantly greater in babies fed $\geqslant 3$ hourly than in babies fed 1 hourly. The feed volume was greater in babies fed $\geqslant 3$ hourly than in those fed 1 and 2 hourly. The postnatal age of babies fed 1,2 , or $\geqslant 3$ hourly was not significantly different at the time of study (table 1). All babies had been

R J Levin

Department of Medical Physics, Leicester Royal Infirmary D H Evans

Table 1 Characteristics of babies recruited for feed study experiments (Data are mean (SEM))

\begin{tabular}{llllllll}
\hline $\begin{array}{l}\text { Feed interval } \\
\text { (hours) }\end{array}$ & $\begin{array}{l}n= \\
\text { (babies) }\end{array}$ & s (studies) & $\begin{array}{l}\text { Postnatal age } \\
\text { (days) }\end{array}$ & $\begin{array}{l}\text { Feed volume } \\
(\mathrm{ml})\end{array}$ & $\begin{array}{l}\text { Gestation } \\
\text { (weeks) }\end{array}$ & $\begin{array}{l}\text { Birthweight } \\
(\mathrm{kg})\end{array}$ & $\begin{array}{l}\text { Study weight } \\
(\mathrm{kg})\end{array}$ \\
\hline 1 & 13 & 27 & $26(3)$ & $10(1)$ & $29(1)$ & $1.25(0.13)$ & $1.26(0.05)$ \\
2 & 11 & 13 & $18(5)$ & $21(2)$ & $31(1)$ & $1.48(0.19)$ & $1.59(0.14)$ \\
3 & 31 & 52 & $28(3)$ & $41(2)$ & $31(0.5)$ & $1.50(0.10)$ & $1.81(0.10)$ \\
$>3$ & 6 & 11 & $31(6)$ & $63(4)$ & $32(1)$ & $1.78(0.22)$ & $2.08(0.07)$ \\
$\geqslant 3$ & 37 & 63 & $29(3)$ & $45(2)$ & $31(0.5)$ & $1.50(0.10)$ & $1.87(0.05)$ \\
\hline
\end{tabular}




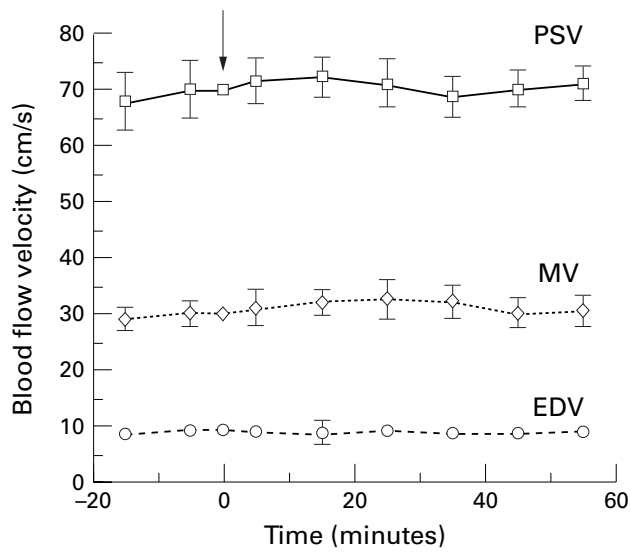

Figure 1 Effect of hourly bolus feeding on blood flow velocity in the superior mesenteric artery. Data are mean (SEM). Where error bar is absent, it is within plotted symbol. Arrow indicates feed. PSV: peak systolic velocity; $M V$ : mean velocity; EDV: end diastolic velocity.

stable on a feeding protocol for at least 24 hours before study.

FEEDS

Of 27 one hourly feed studies, six were after expressed breast milk (EBM); nine after Prematil with Milupan (Prematil); four after Cow and Gate Low Birthweight Formula (C\&G); and eight after Cow and Gate Nutriprem (C\&G NP).

Of 13 two hourly feed studies, six were after EBM; three after Prematil; two after C\&G; and two after C\&G NP.

Of $63 \geqslant 3$ hourly feed studies, 26 were after EBM; 19 after Prematil; seven after C\&G; seven after C\&G NP; and four after SMA Low Birthweight Formula (SMA LBWF).

BLOOD FLOW VELOCITY MEASUREMENT

An ATL Mark 4 duplex pulsed wave ultrasound machine was used to interrogate the splanchnic vessels. A $5 \mathrm{MHz}$ probe was held just below the xiphisternum, to visualise the coeliac axis and SMA in the sagittal plane. The angle of insonation was kept between $0^{\circ}$ and $30^{\circ}$ and recordings were made just distal to the vessel origin at the abdominal aorta, as the diameter of the vessel at this point changes minimally after feeding, ${ }^{2}$ so blood flow velocity will provide a true representation of blood flow. Due to the possibility of variation of splanchnic blood flow velocity with time in a resting neonate, similar to that described for the cerebral circulation, ${ }^{10}$ not less than 15 consecutive pulses were accepted for analysis. Each Doppler recording was assessed on the basis of both its visual and audible characteristics and was saved to stereo video tape for subsequent analysis.

For each feed study the baby was studied serially at 10 minute intervals for 20 minutes before feeding and for 60 minutes ( 1 hourly studies), 90 minutes (2 hourly studies), or 120 minutes ( $\geqslant 3$ hourly studies) postprandially. Data were pooled into 10 minute bins and are presented as mean values at $5,15,25,35$, etc. minutes postprandially and at -5 and -15 minutes preprandially.

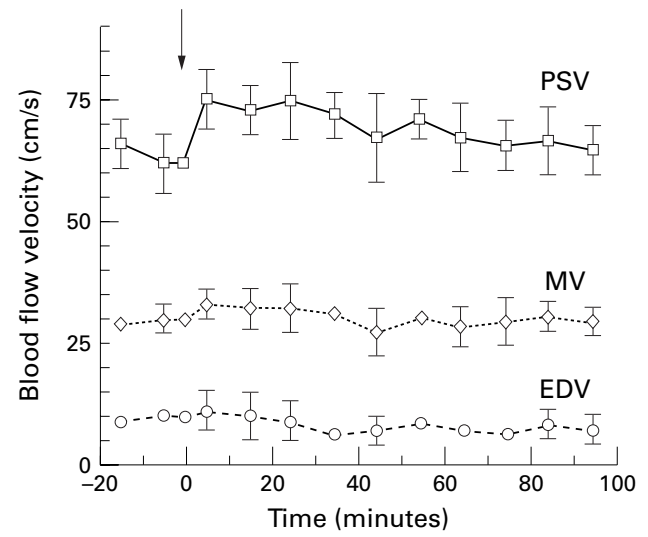

Figure 2 Effect of 2 hourly bolus feeding on blood flow velocity in the superior mesenteric artery. Data are mean (SEM). Where error bar is absent, it is within the plotted symbol. Arrow indicates a feed.

The Doppler signals were analysed in three stages using a Doppler signal analysis package which permitted further selection of suitable sections of Doppler recording. Values of the peak systolic velocity (PSV), mean velocity (MV), and end diastolic velocity (EDV) are presented.

Statistical comparisons were made between data points using Student's $t$ tests. "Spurious significance" resulting from multiple $t$ tests using the same dataset was corrected for using the Bonferroni procedure. ${ }^{11}{ }^{12}$ Pearson's correlation coefficient ( $r$ ) was used to describe correlations between feed volume and postprandial response.

\section{Results}

EFFECT OF FEED INTERVAL

There was no change in PSV, MV, EDV in the coeliac axis associated with 1 hourly bolus feeding. The preprandial values were 56, 26, and $7 \mathrm{~cm} / \mathrm{s}$, respectively. Fig 1 shows the effect of 1 hourly bolus feeding on SMA blood flow velocity. As with the coeliac axis, there was no postprandial hyperaemia but the preprandial PSV was significantly higher in the SMA than in the coeliac axis $(70$ vs $56 \mathrm{~cm} / \mathrm{s} ; \mathrm{p}<0.01)$.

There was no change in PSV, MV, EDV in the coeliac axis with 2 hourly feeds. The preprandial PSV was not significantly different from that associated with 1 hourly feeds (57 vs $56 \mathrm{~cm} / \mathrm{s} ; \mathrm{p}>0.1)$. The preprandial PSV in the SMA was lower in babies fed 2 hourly than in those fed 1 hourly (62 vs $70 \mathrm{~cm} / \mathrm{sec}$ ) but this difference was not significant $(p>0.05)$. The SMA PSV increased postprandially by 14 (3) $\mathrm{cm} / \mathrm{s} \quad(\mathrm{p}<0.05)$ and the MV by $8(2) \mathrm{cm} / \mathrm{s}$ $(p<0.05)$; there was no postprandial change in SMA EDV (fig 2).

Babies fed at an interval of $>3$ hours showed the same postprandial response as those fed 3 hourly. The preprandial PSV in the SMA was not significantly different (> 3 hourly, 49 vs 3 hourly, $55 \mathrm{~cm} / \mathrm{s} ; \mathrm{p}>0.05)$ and both groups showed the same maximum postprandial PSV (77 vs $74 \mathrm{~cm} / \mathrm{s} ; \mathrm{p}>0.1$ ) and latency of maximum response ( 25 vs 23 minutes; $p>0.1$ ). The babies in the two groups were not significantly different with respect to gestational age, birthweight, postnatal age or study weight. 


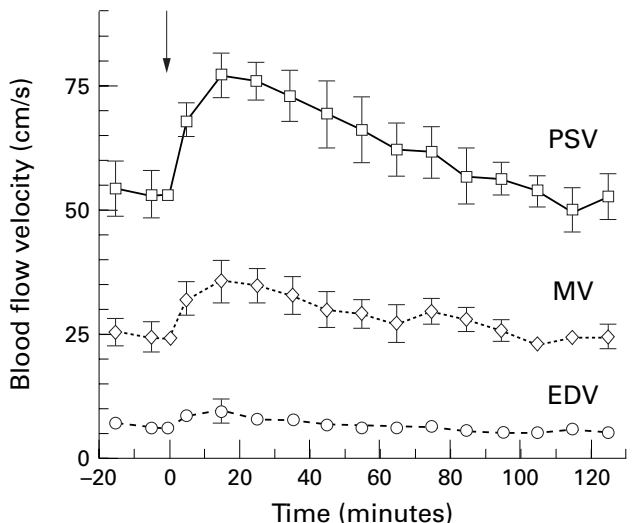

Figure 3 Effect of $\geqslant 3$ hourly bolus feeding on blood flow velocity in the superior mesenteric artery. Data are mean (SEM). Where error bar is absent, it is within the plotted symbol. Arrow indicates a feed.

These data were therefore pooled to form one group of babies fed $\geqslant 3$ hourly (table 1 ). In the coeliac axis there was no change in any velocity parameter after $\geqslant 3$ hourly feeding and the preprandial PSV was not significantly different from that in babies fed 1 and 2 hourly (58 vs 56 and $57 \mathrm{~cm} / \mathrm{s} ; \mathrm{p}>0.1)$. The preprandial coeliac axis PSV was not significantly different from that for the SMA in this group of babies fed $\geqslant 3$ hourly ( 58 vs $53 \mathrm{~cm} / \mathrm{s} ; \mathrm{p}>0.1$ ).

In the SMA of babies fed $\geqslant 3$ hourly the preprandial PSV was significantly less than in babies fed 1 hourly (53 vs $70 \mathrm{~cm} / \mathrm{s} ; \mathrm{p}<0.01$ ). There was a large and significant postprandial increase in PSV $(25(4) \mathrm{cm} / \mathrm{s} ; \mathrm{p}<0.05)$ and $\mathrm{MV}$ (11(2) $\mathrm{cm} / \mathrm{s} ; \mathrm{p}<0.05)$ but no change in EDV (fig 3). The increase in SMA PSV after feeding in babies fed $\geqslant 3$ hourly was greater than in those fed 2 hourly (25 vs $14 \mathrm{~cm} / \mathrm{s} ; \mathrm{p}<0.05$ ) and returned to preprandial values after about 100 minutes (fig 3).

EFFECT OF FEED TYPE

Based on their complement of long chain polyunsaturated fatty acids, the data from babies fed Prematil and C\&G NP were pooled as were the data from babies fed $C \& G$ and SMA LBWF. Both of these groups were compared with EBM. The resultant three groups are referred to as EBM, F+LCP (formulas containing long chain polyunsaturated fatty acids), and F-LCP (formulas without). There was no difference in the response of the coeliac axis or SMA to 1 or 2 hourly bolus feeding or of the coeliac axis to $\geqslant 3$ hourly feeding due to feed type. However, the response of the SMA to $\geqslant 3$ hourly feeding depended on feed type. The postprandial hyperaemia after EBM had longer latency (time to peak change) and smaller amplitude (size of peak change) than both F+LCP and F-LCP which were not significantly different from each other (42 vs 29 and 26 minutes; $\mathrm{p}<0.05 ; 25$ vs 32 and $30 \mathrm{~cm} / \mathrm{s}$; $\mathrm{p}<0.05$ ) (fig 4).

EFFECT OF FEED VOLUME

There was no correlation between feed volume and maximum postprandial hyperaemia for EBM $(r=0.20)$ or formula feeds $(r=-0.19)$ in babies fed $\geqslant 3$ hourly.

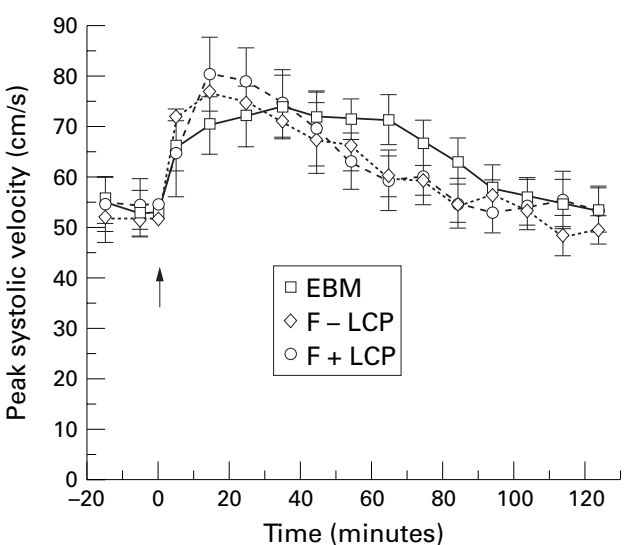

Figure 4 Effect of $\geqslant 3$ hourly bolus feeds of formulas with long chain polyunsaturated fatty acids $(F+L C P)$ or without (F-LCP) and expressed breast milk on peak systolic velocity in the superior mesenteric artery. Data are mean (SEM). Where error bar is absent, it is within plotted symbol. Arrow indicates a feed.

\section{Discussion}

These data show, for the first time, the importance of feed interval on splanchnic perfusion in human preterm neonates and confirm that their splanchnic vessels respond to enteral feeding in a qualitatively similar way to those of adults as long as the feed interval is sufficient to permit a maximal postprandial response $(\geqslant 3$ hours).

Studies of the response of the splanchnic circulation to enteral feeding have concentrated on bolus feeds with a large interfeed interval. Such studies have shown large postprandial mesenteric hyperaemias which tend to be of similar duration in human adults $(>1 \text { hour })^{24}$ and neonates ( $1 \frac{1 / 2}{2}$ hours). ${ }^{7}$ Martinussen et $a l^{13}$ described circulatory responses to feeding in preterm infants. They comment on the importance of feed interval on SMA blood flow velocity and suggest that higher preprandial blood flow velocities in preterm rather than term babies may be a result of more frequent feeding in the former group. We have described a gradation of the response of the SMA to a range of feed intervals. The preprandial PSV is inversely related to feed interval and the postprandial response shows a direct correlation with feed interval. These patterns imply a tetanic response to a decreasing feed interval whereby the preprandial level in babies fed 1 hourly increases to almost the same level as the peak postprandial level associated with $\geqslant 3$ hourly feeds. Such a preprandial hyperaemia excludes the possibility of any subsequent further increase in blood flow velocity after a feed, resulting in a persistent hyperaemia in babies fed 1 hourly.

In adults the composition of a bolus feed has significant effects on the postprandial mesenteric hyperaemia. Contradictions do exist, but there is a general consensus that dietary fat provides the greatest stimulus to human intestinal blood flow, ${ }^{4}$ although Qamar and Read ${ }^{1}$ reported no difference in the amplitude of the response to fat, protein, or carbohydrate. In particular, it has been proposed that long chain fatty acids are especially important as a hyperaemic stimulus. ${ }^{414}$ Protein causes the smallest 
amplitude of postprandial response and the response to carbohydrate is faster than that after either protein or fat. ${ }^{14}$ We have shown a smaller amplitude and longer latency of response to expressed breast milk (EBM) than preterm formula feeds with or without long chain polyunsaturated fatty acids (LCPs). Preterm human milk has a lower caloric value than the formulas used in this study which reflects the consistently lower amounts of protein and carbohydrate in preterm human milk. The lower content of carbohydrate in human preterm milk correlates with a decreased latency of postprandial response.

The slightly higher fat content of the formula feeds is unlikely to have accounted for the increased postprandial hyperaemia associated with these feeds compared with expressed breast milk. However, it has been suggested that long chain fats are especially potent stimulators of the postprandial response, ${ }^{14}$ a fact which is not borne out by this study. In preterm human neonates the addition of LCPs to preterm formula does not modify the postprandial hyperaemia which remains significantly different from that after a feed of expressed breast milk. In fact, formula feeds which do not contain LCPs provoke a larger amplitude of response than expressed breast milk which does contain them.

The effect of nutrient types on intestinal motility and gastric emptying is well documented. Increasing amounts of fat lead to feedback inhibition of gastric emptying ${ }^{15}$ and an ileal brake was described by Spiller et al, ${ }^{16}$ the phenomenon by which ileal infusion of partially digested triglyceride inhibits jejunal motility. Sidery et $a l^{17}$ investigated the effect of high fat and high carbohydrate meals on gastric emptying in human adults and simultaneously monitored superior mesenteric blood flow. They confirmed that a high fat meal leads to a mesenteric hyperaemia which has a longer latency of peak response than an isocaloric and isovolaemic meal which is high in carbohydrate, but there was no difference in the amplitude of the postprandial response. The time at which $50 \%$ of the fat meal had left the stomach was $1 \frac{1}{2}$ times that of the high carbohydrate meal. These data suggest a relation between the rate of emptying of chyme into the duodenum and the mesenteric blood flow response but show no relation between the magnitude of this response among feed types.

Several studies have addressed the issue of gastric emptying in neonates. Billeaud et al ${ }^{18}$ showed that there was no difference in gastric emptying between babies with and without gastro-oesophageal reflux when fed the same type of milk, and that differences in gastric emptying reflected differences in feed type. Ewer $e t a l^{19}$ have shown that gastric emptying is significantly faster following feeds of breast milk than formula feeds due to the higher fat content of the formulas, but McClure and Newell ${ }^{20}$ have shown that fortification of breast milk has no effect on gastric emptying in preterm neonates.

As well as the chemical composition of the meal, its osmotic properties may be important in the control of the postprandial hyperaemia, but published findings are contradictory. Nonabsorbable osmotic agents can cause hyperaemia in adults ${ }^{4}$ but have no effect in dogs. ${ }^{21}$ Any osmotic effect is likely to be small and Qamar and $\operatorname{Read}^{1}$ did not control their experiment for osmolarity as they believed that it "is likely to have no major effect on SMABF" (superior mesenteric artery blood flow). The feeds used in this study were all of similar osmolarity.

The volume of a feed may have a role in determining the magnitude of the postprandial response. Coombs et $a l^{6}$ reported no difference in the response of the gut vessels of term neonates to feeds which ranged from $25 \mathrm{ml}$ to $100 \mathrm{ml}$. Few studies have considered this variable in depth as they have tended to use isovolaemic feeds to minimise variables. We have shown that there is no correlation between feed volume and maximum postprandial increase in PSV in preterm babies fed either EBM or preterm formulas.

This study shows that feed interval and feed type have large and significant effects on splanchnic perfusion in preterm human neonates. Babies fed 1 hourly display a persistent mesenteric hyperaemic state and the addition of LCPs to preterm formulas has no effect on the postprandial response. These effects and other observations of splanchnic variability and significant differences that depend on postnatal age as well as on enteral or parenteral feeding protocol (unpublished data) should be considered in any study of gut blood flow in neonates. No experimental designs to date have adequately controlled for all of these variables, all of which exert important and significant effects.

We thank the special care nursing staff at the Jessop Hospital for Women and the parents of the babies recruited for the study. AJPL was supported by MILUPA.

1 Qamar MI, Read AE. Effects of ingestion of carbohydrate, fat, protein, and water on the mesenteric blood flow in fat, protein, and water on the mesenteric
man. Scand f Gastroenterol 1988;23:26-30.

2 Lilly MP, Harward TRS, Flinn WR, Blackburn DR, Astleford PM, Yao JST. Duplex ultrasound measurement of changes in mesenteric flow velocity with pharmacologic and physiologic alteration of intestinal blood flow in man. F Vasc Surg 1989;9:18-25.

3 Qamar MI, Read AE, Skidmore R. Transcutaneous Doppler ultrasound measurement of coeliac axis blood flow in man. BrF Surg 1985;71:391-3.

4 Moneta GL, Taylor DC, Helton WS, Mulholland MW, Strandness DE Jnr. Duplex ultrasound measurement of postprandial blood flow: effect of meal composition. Gastroenterology 1988;95:1294-301.

5 Hsu CH, Lee HC, Huang FY. Duplex ultrasonographic assessment of gut blood flow velocity: effect of meal composition in normal full-term newborns after first feed. $\mathcal{F}$ position in normal full-term new

6 Coombs RC, Morgan MEI, Durbin GM, Booth IW, McNeish AS. Doppler assessment of human neonatal gut
Mcmbs RC, Morgan MEI, Durbin GM, Booth IW, blood flow velocities: postnatal adaptation and response to feeds. F Pediatr Gastroententerol Nutr 1992;15:6-12.

7 Leidig E. Doppler analysis of superior mesenteric artery blood flow in preterm infants. Arch Dis Child 1989;64:47680.

8 Gladman G, Sims DG, Chiswick ML. Gastrointestinal blood flow velocity after the first feed. Arch Dis Child 1991;66:17-20.

9 Kempley ST, Gamsu HR, Vyas S, Nicolaides K. Effects of intrauterine growth retardation on postnatal visceral and cerebral blood flow velocity. Arch Dis Child 1991;66:111518.

10 Coughtrey H, Rennie JM, Evans DH. Postnatal evolution of slow variability in cerebral blood flow velocity. Arch Dis Child 1992;67:412-15.

11 Elashoff JD. Down with multiple $t$-tests! Gastroenterology 1981;80:615-20.

12 Ludbrook J. On making multiple comparisons in clinical and experimental pharmacology and physiology. Clin Exp Pharmacol Physiol 1991;18:379-92. 
13 Martinussen M, Brubakk A-M, Vik T, Yao AC. Mesenteric blood flow velocity and its relation to transitional circulatory adaptation in appropriate for gestational age preterm infants. Pediatr Res 1996;39:275-80.

14 Chou CC, Kvietys PR. Physiological and pharmacological alterations in gastrointestinal blood flow. In: Granger DN, Bulkley GB, eds. Measurement of blood flow: applications to the splanchnic circulation. Baltimore: Williams \& Williams, 1981:477-509.

15 Brown NJ, Read NW, Richardson A, Rumsey RDE, Bogentoft C. The characteristics of lipid substances activating the ileal brake in the rat. Gut 1990;10:1126-12.

16 Spiller RC, Trotman IF, Higgins BE. The ileal brake - inhibition of jejunal motility after ileal fat perfusion in man. Gut 1984;25:365-74.
17 Sidery MB, Macdonald IA, Blackshaw PE. Superior mesenteric artery blood flow and gastric emptying in humans and the differential effects of high fat and high carbohydrate meals. Gut 1994;35:186-90.

18 Billeaud C, Guillet J, Sandler B. Gastric emptying in infants with or without gastro-oesophageal reflux according to the type of milk. Eur f Clin Nutr 1990;44:577-83.

19 Ewer AK, Durbin GM, Morgan MEI, Booth IW. Gastric emptying in preterm infants. Arch Dis Child 1994;71:F24F7.

20 McClure RJ, Newell SJ. Effect of fortifying breast milk on gastric emptying. Arch Dis Child 1996;74:F60-F2.

21 Kvietys PR, Pittman RP, Chou CC. Contribution of luminal concentration of nutrients and osmolarity to postprandial intestinal hyperaemia in dogs. Proc Soc Exp Biol Med 1976;152:659-63. 